Andrie Jeremy Formanez, MD

Grace Naomi B. Galvan-Bravo, MD

Department of Otorhinolaryngology

Head and Neck Surgery

Armed Forces of the Philippines Medical Center

Quezon City, Philippines

\section{Gastrointestinal Stromal Tumor of the Tongue}

\author{
ABSTRACT \\ Objective: To report a case of a gastrointestinal stromal tumor presenting as a recurrent tongue \\ mass \\ Methods:
}

Study Design: Case Report

Setting: Tertiary Public Military Hospital

Participant: One patient

Results: A 40-year-old Filipino soldier from Camarines Sur presented with a recurrent tongue mass two years after excision of a progressively-enlarging, firm, fixed, non-tender mass at the left posterior third of the tongue diagnosed as a Schwannoma. Repeat surgery involved partial glossectomy via midline mandibular swing. Final histopathologic report after immunohistochemical studies for CD117, SMA, and S100 was extraintestinal gastrointestinal stromal tumor of the tongue. The patient was started on the c-kit tyrosine kinase inhibitor Imatinib with no recurrence 10 months post treatment.

Conclusion: Gastrointestinal stromal tumor may be considered when presented with a recurrent tongue mass despite complete surgical resection. Surgical removal is curative for most lesions. Post-operative chemotherapy with the use of Imatinib is valuable.

Keywords: recurrent tongue mass, gastrointestinal stromal tumor, immunohistochemistry, c-kit tyrosine kinase inhibitor

A 40-year-old Filipino soldier from Camarines Sur presented with a recurrent mass over the posterior third of the tongue. His condition started two years earlier, with a progressively enlarging, firm, fixed, non-tender mass at the left posterior third of the tongue of one month duration, associated with difficulty in speech and dysphagia for solid food. There was no history of trauma, weight loss or taste disturbances.

Initial physical examination revealed a $5 \times 5 \times 3 \mathrm{~cm}$, non-hyperemic, non-tender, firm, fixed mass involving the left posterior third of the tongue with no limitation of tongue movement. There were no palpable cervical lymphadenopathies, and the rest of the physical examination findings were unremarkable.

Incision biopsy revealed capillary hemangioma, and intralesional Triamcinolone injection at $1.5 \mathrm{cc}$ once a week for four weeks was started. A decrease in size of the mass to $4 \times 3 \times 3 \mathrm{~cm}$ was noted, and wedge excision biopsy with $0.5 \mathrm{~cm}$ margins and primary repair was performed under general anesthesia. Histopathological examination showed tissue composed of spindle-shaped cells with indistinct cellular borders disposed in fascicles while others exhibit rows of cells with 


\section{CASE REPORTS}

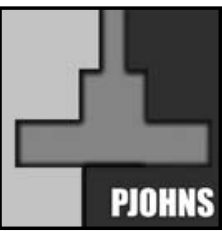

nuclear palisading alternating with anuclear fibrillar zones; and chronic inflammation of the surrounding muscular stroma. The histopathologic interpretation was schwannoma with chronic glossitis.

Two years later, a month prior to this admission, he noted recurrence of the mass in the same area of the tongue with associated dysphagia, odynophagia and slurring of speech. Physical examination revealed a $5 \times 4 \times 2 \mathrm{~cm}$ exophytic, nonhyperemic, nontender, firm mass over the midline of the posterior $3^{\text {rd }}$ of the tongue. (Figure 1). There were

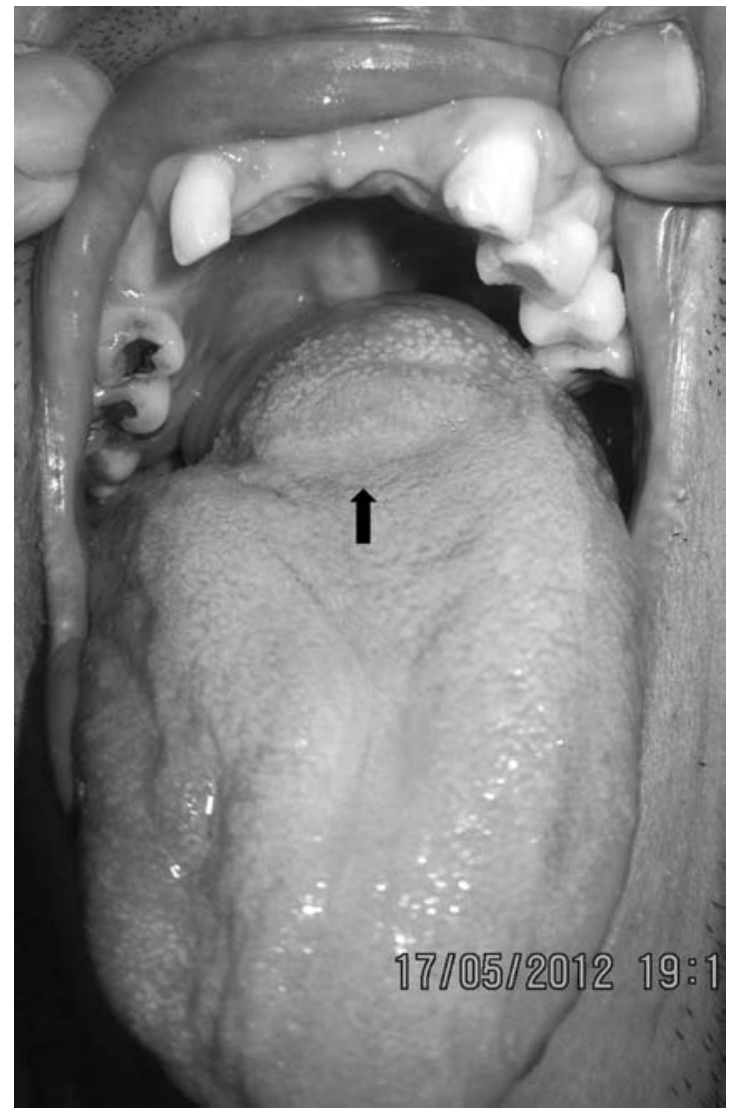

Figure 1. $5 \times 4 \times 2 \mathrm{~cm}$ exophytic, nonerythematous, nonhyperemic, nontender, firm mass over the midline of the posterior third of the tongue (arrow)

no palpable cervical lymphadenopathies and the rest of the physical examination was again unremarkable. Contrast CT scans of the oropharynx and neck revealed a fairly well-defined solid tumor in the posterior half of the left and right tongue causing secondary narrowing of the oral cavity and oropharynx. (Figure $2 A, B$ )

A partial glossectomy excised the mass with $0.5 \mathrm{~cm}$ margins via a midline mandibular swing with titanium plate restorative fixation. Resection borders extended past the sulcus terminalis anteriorly and approached tongue base posteriorly. The gross specimen was a firm encapsulated $7 \times 7 \times 8 \mathrm{~cm}$ mass. (Figure $3 A, B$ )
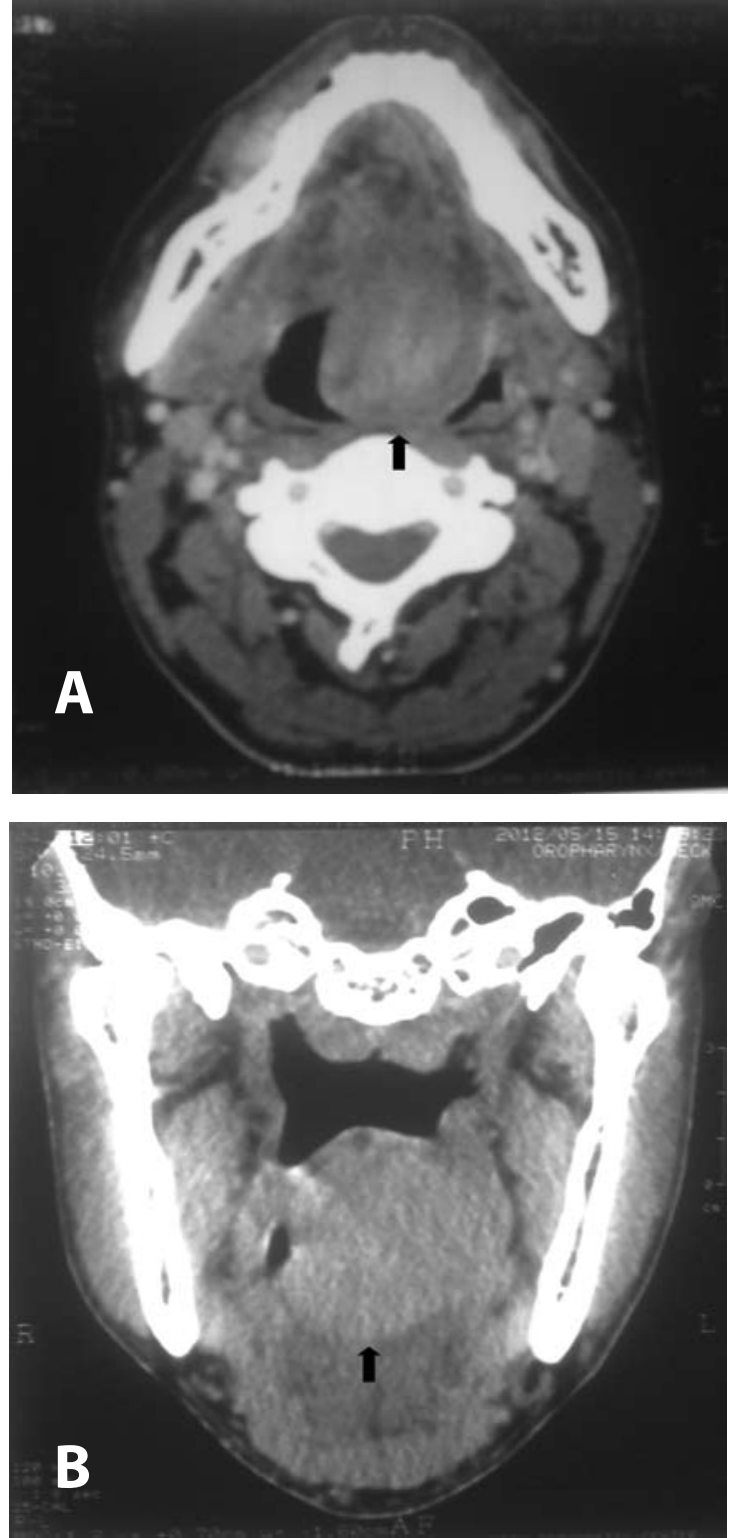

Figure 2. Contrast CT scan of oropharynx, A. axial view, B. coronal view, showing a fairly well-defined contrast-enhancing mass involving the posterior half of the left tongue which crosses to the right, measuring $5 \times 4 \times 5 \mathrm{~cm}$ (arrow)

Histopathological examination showed mostly bundles of normal skeletal muscle tissues with some portions of stroma noted to have densely cellular fascicles and intersecting bundles of spindle shaped cells, exhibiting vesicular to hyperchromatic nuclei, some wavy, with pinpoint nucleoli and scanty pinkish cytoplasm. The tumor cells were pleomorphic, exhibiting fusiform vesicular to hyperchromatic nuclei, pinpoint nucleoli, and eosinophilic cytoplasm; other cells appeared asymmetrically tapered, spindly with irregular nuclei in palisading form; still other tumor cells were monotonous, oval shaped with illdefined borders. Areas of necrosis and inflammation were noted in 

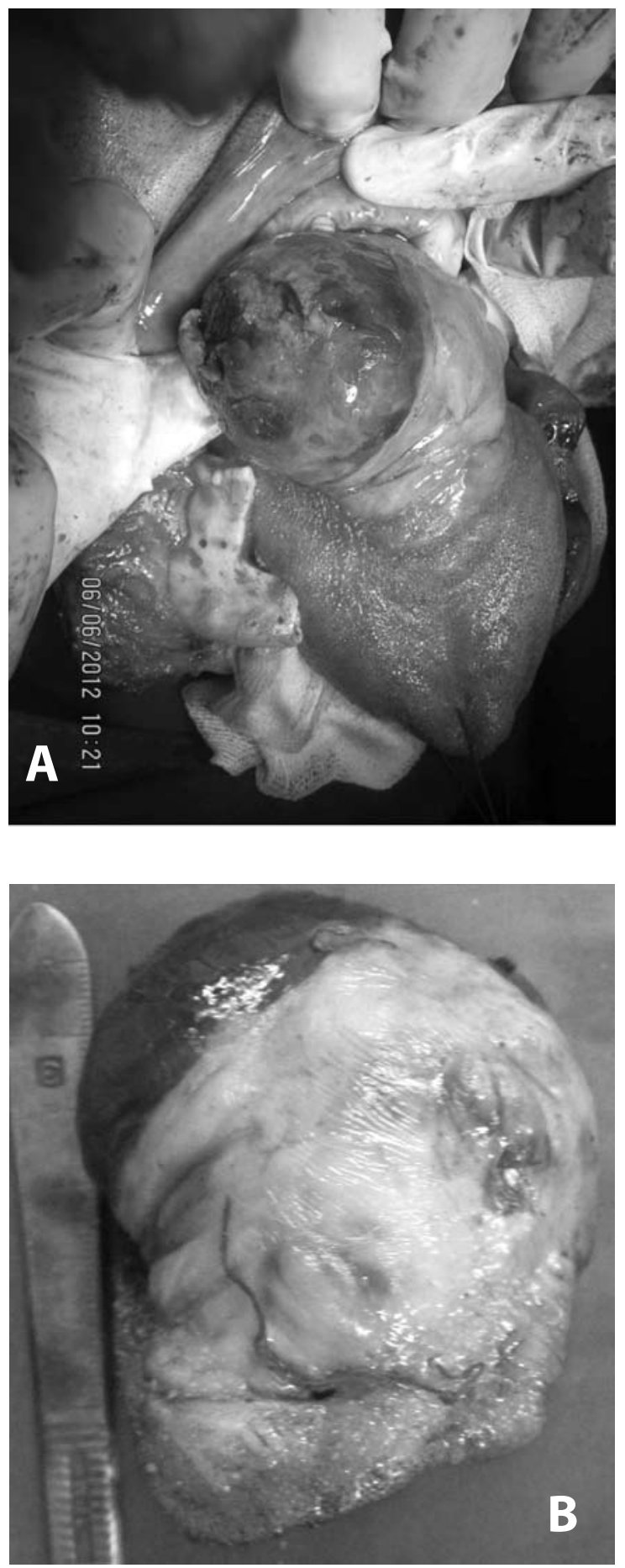

Figure 3. Firm encapsulated $7 \times 7 \times 8 \mathrm{~cm}$ mass, $A$, intraoperative view and $B$. gross specimen

some portions of the overlying epithelium. Mitotic figures were seen at $1-3 /$ high power field. The portions of distal margins of resection were negative for tumor metastases. (Figure $4 A-B$ )

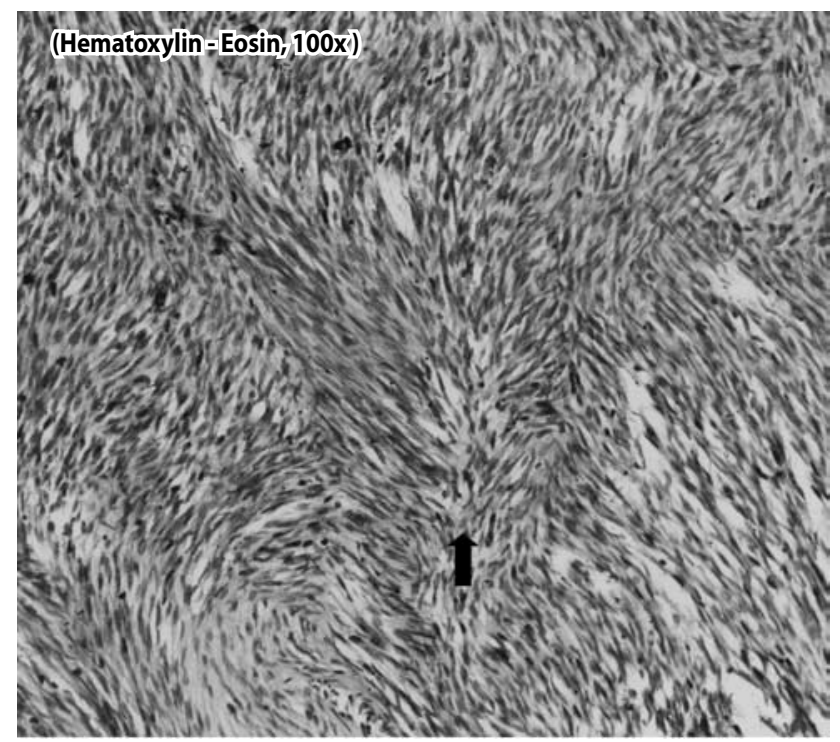

Figure 4A. Low power magnification (100x), H\&E, showing densely cellular fascicles and intersecting bundles of spindle shaped cells (arrow)

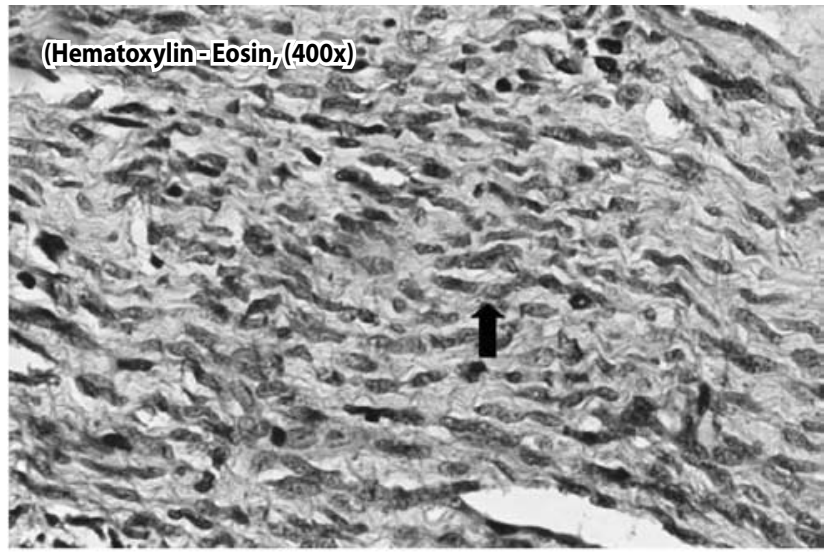

Figure 4B. High power magnifaction $(400 \mathrm{x}), \mathrm{H} \& \mathrm{E}$, showing spindle shaped cells exhibiting wavy hyperchromatic nuclei with pinpoint nucleoli and scanty pinkish cytoplasm (arrow)

Initial histopathological interpretation was a malignant spindle cell tumor with the following considerations: 1) malignant peripheral nerve sheath tumor; 2) myofibroblastic sarcoma; and 3) spindle cell (sarcomatoid) carcinoma. Immunohistochemical studies for S-100, Smooth muscle actin, Desmin, CD34, Factor VIII and Cytokeratin were conducted, CD117, S100 and SMA were positive (Figure 4 C - E). The final histopathological and immunohistochemical diagnosis was extraintestinal gastrointestinal stromal tumor.

On the $24^{\text {th }}$ post-operative day, a $2 \times 2 \times 0.5 \mathrm{~cm}$ exophytic, nonerythematous, firm, nontender, fixed recurrent mass was noted over the midline of the anterior tongue. (Figure 5) The oncology service started Imatinib $100 \mathrm{mg} / \mathrm{tab}, 4$ tablets once daily, with regression of the mass, and no recurrence until 10 months post treatment. 
CASE REPORTS

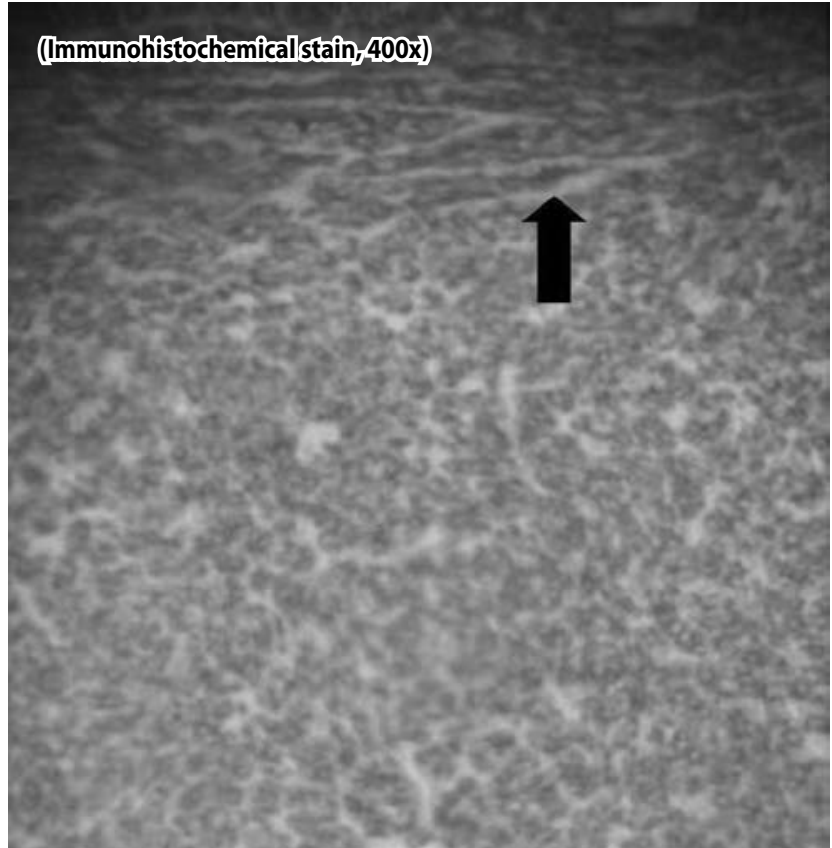

Figure 4C. Low power magnifaction (400x), immunohistochemical stain, showing positive, diffuse strong cytoplasmic expression in neoplastic cells for smooth muscle actin (SMA) (arrow)

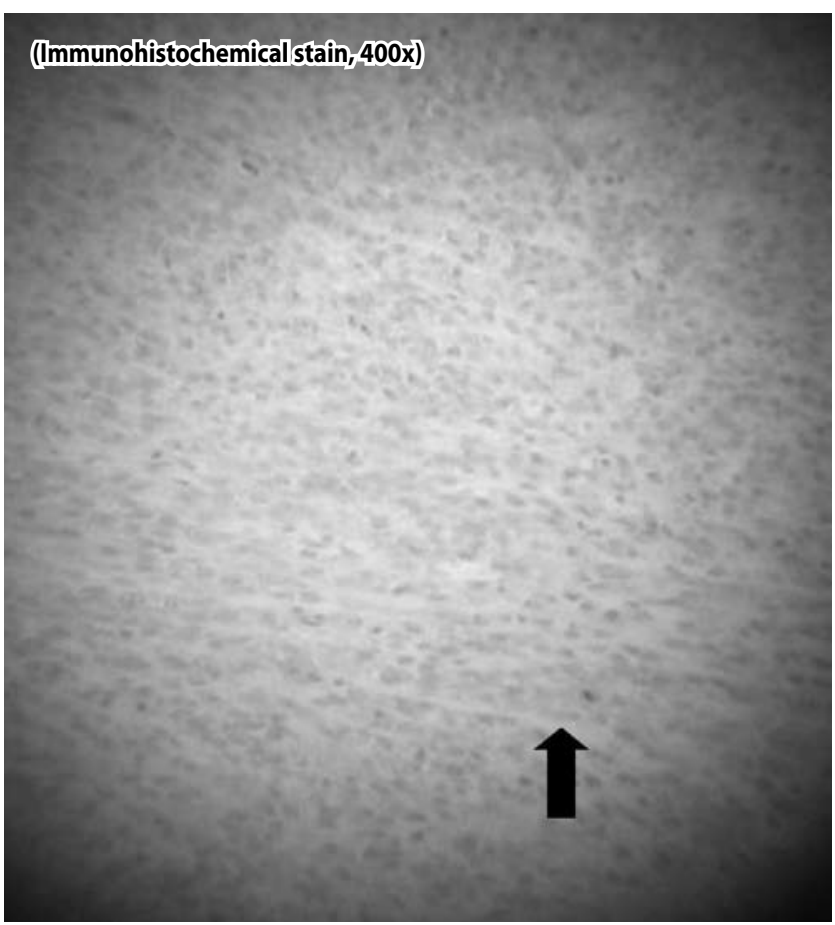

Figure 4D. Low power magnifaction (400x), immunohistochemical stain, showing positive, diffuse cytoplasmic expression in neoplastic cells for CD117 (arrow)

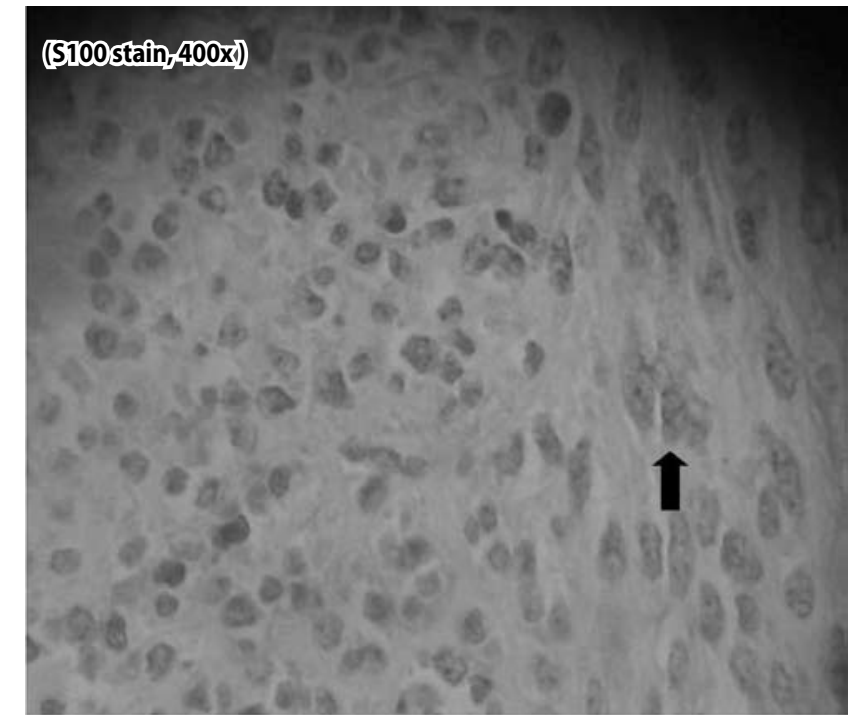

Figure 4E. Immunohistochemical stian, 400x showing positive, cytoplasmic and nuclear staining in neoplastic cells for $\mathrm{S} 100$ (arrow)

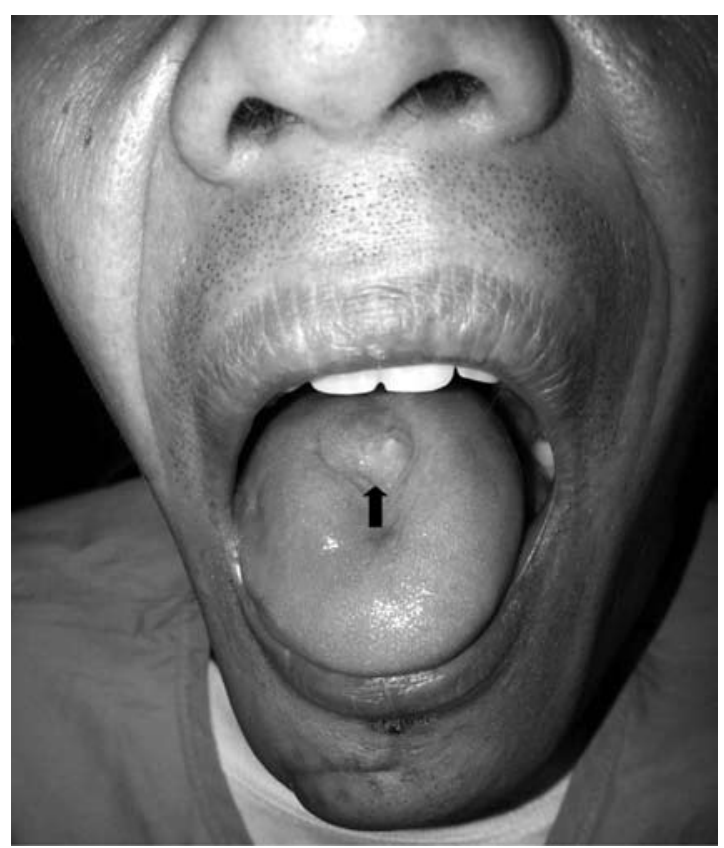

Figure 5. Recurrent $2 \times 2 \times 0.5 \mathrm{~cm}$ exophytic, nonerythematous, firm, nontender, fixed mass over the midline of the anterior tongue (arrow)

\section{DISCUSSION}

Gastrointestinal stromal tumors (GIST) are nonepithelial neoplasms which arise from connective tissue. These are said to arise from the interstitial cells of Cajal.' Such cells are normally part of the autonomic nervous system of the lower digestive tract and serve a pacemaker function in controlling motility. 


\section{CASE REPORTS}

Although GIST are among the most common mesenchymal tumors of the digestive tract, they rarely occur in the tongue. Approximately $70 \%$ arise in the stomach, $20 \%$ in the small intestine, and less than $10 \%$ in the esophagus. ${ }^{2}$ To the best of our knowledge, there has been only one previous report in the English literature of a malignant GIST of the tongue in a 60-year old woman in Kuwait. ${ }^{3}$

Differential diagnosis in this patient presenting with a recurrent tongue mass include schwannoma, squamous cell carcinoma of the tongue, and malignant peripheral nerve sheath tumor.

A schwannoma is a benign encapsulated tumor which can arise anywhere in the body with a high predilection for the head and neck region that usually occurs in persons between $40-70$ years of age. ${ }^{4}$ Microscopic examination reveals Antoni $A$ and $B$ patterns with elongated cells with cytoplasmic processes arranged in fascicles in areas of moderate to high cellularity with little stromal matrix. ${ }^{4}$ However, it is slightly more common in women and is usually found at the base of the tongue, and recurrence upon complete resection of the mass is rare.

With a 4 pack-year smoking history, squamous cell carcinoma of the tongue can be considered. It usually presents as a painless, ulcerative or infiltrative lesion at the ventrolateral aspect of the mid and posterior tongue, ${ }^{5}$ but can also present as an exophytic lesion with symptoms of dysphagia, odynophagia, and difficulty of speech. Squamous cell carcinoma can recur with inadequate resection and/or adjuvant medical treatment. However, it was ruled out by our histopathologic results.

Malignant peripheral nerve sheath tumors arise from cells associated with the nerve sheath namely Schwann cells, perineural cells, or fibroblasts. ${ }^{6}$ Although these commonly present as enlarging masses near the sciatic, brachial and sacral plexuses, they may also present as intraoral masses and may involve the tongue. ${ }^{6}$ Their etiology is unknown, but their incidence is increased in patients with a history of radiation exposure. ${ }^{6}$ They usually occur in adults $20-50$ years of age and symptoms are usually related to impingement of the involved nerve or mass effect. ${ }^{6}$ Histologically, these may appear as dense cellular fascicles containing spindle shaped cells and may have a nuclear palisading as was seen in the patient. ${ }^{6}$ However, they are not positive for CD117 on immunohistochemistry, hence this entity was ruled out.

Symptoms in patients with GIST may be related to mass effects. They may present with difficulty in swallowing, vague abdominal pain or discomfort, or gastrointestinal hemorrhage in cases of mucosal ulceration. Only the first symptom was observed in our patient due to the location of the tumor on the tongue.

Most GIST arise because of a mutation in a gene which is responsible for encoding a transmembrane receptor for a growth factor called stem cell factor (scf). ${ }^{1}$ This gene is called c-kit and its product CD117 is expressed on the interstitial cells of Cajal, mast cells, melanocytes and bone marrow cells. ${ }^{1}$

Activating mutations of c-kit and platelet derived growth factor alpha (PDGFRA) permit the phosphorylation of the receptor tyrosine kinases perpetuating the receptor-initiated signal and causing activation of the downstream effectors. The end result of such activation is increase in cellular proliferation and decrease in apoptosis, ultimately leading to neoplasia, probably following other, currently unknown genetic events. ${ }^{1}$

Due to the sparsity of data regarding extraintestinal GIST, particularly the tongue in this case, histogenesis is not yet defined. For primary GIST of mesentery, omentum, and retroperitoneum, where interstitial cells of Cajal are not known to be present, it has been suggested that a new type of c-kit positive mesenchymal cell may be present ${ }^{7}$ and this could also be a possibility in explaining the development of GIST in the tongue of our patient.

GIST typically originate from within the muscle wall of the gastrointestinal tract, ranging from $1-40 \mathrm{~cm}$ in size with an average size of approximately $5 \mathrm{~cm}$. Small GIST usually form subsolid intramural masses but may also have polypoid morphology. When present in the abdominal cavity, as is usually the case, large GIST are usually exophytic with an outward pattern of growth. ${ }^{8}$

For the most part, the etiology for GIST remains unknown at present. The vast majority of GIST are sporadic. ${ }^{9}$ Familial GIST occurs rarely and is associated with a mutation in the c-kit or even more rarely in succinate dehydrogenase genes in Carney-Stratakis syndrome. ${ }^{10}$ Mutation of the PDGFRA gene is an alternative oncogenic event, and is found in 35\% to $40 \%$ of GIST lacking a c-kit mutation. ${ }^{9}$

GIST has an incidence of $10-20$ per 1 million people. ${ }^{11}$ This would make the GIST the most common form of mesenchymal tumor. There is a slight male predominance. In GIST of the stomach, the peak age of diagnosis is at 60 years with fewer than $10 \%$ occurring in individuals under 40 years of age. ${ }^{8}$ It is equally distributed across all geographic and ethnic groups. ${ }^{4}$

Current classifications do not characterize GIST as benign or malignant. ${ }^{8}$ Rather, these classify tumors according to the probability of recurrence into very low risk, low risk, moderate risk, and high risk. Factors that affect recurrence include tumor size, mitotic index, and tumor location. ${ }^{1}$

Local invasion and metastases indicate aggressive tumor behavior and increases the risk of tumor recurrence. ${ }^{8}$ In the abdomen, spread to the liver, omentum, and peritoneum is usually seen. Metastases to the bone, pleura, lungs, and retroperitoneum may also occur. Occasionally, malignant lymphadenopathy is seen in $<10 \%$ of cases. $^{13}$ Radiologic findings that are suggestive of malignancy include heterogeneous enhancement after contrast enhancement, 


\section{CASE REPORTS}

ulcerations and size $>5 \mathrm{~cm}^{14}$

Based on criteria for GIST propounded by Miettinen and Lasota' with tumor size at $>5 \mathrm{~cm} \leq 10 \mathrm{~cm}$ and mitotic figures at $1-3 /$ high powered field, this tumor is placed in Group 3a which for extragastric tumors would signify a high incidence of recurrence.

Histologically, GIST may exhibit two patterns. Tumors composed of thin elongated cells are classified as spindle cell type while those dominated by epithelial appearing cells are termed epithelioid type. ${ }^{15}$ The spindle cell type may exhibit a palisading architecture and may either have an amphophilic, basophilic or eosinophilic cytoplasm; '1 the latter being true in the patient. Nucleoli are of variable prominence. Areas of necrosis and inflammation are also seen. Immunohistochemistry for GIST would be positive for CD117 and S100. ${ }^{16}$ These markers were positive for this patient.

Mazur and Clark first recognized GIST as a distinct clinicopathologic syndrome in $1983 .{ }^{16}$ Previously, GIST were often diagnosed as smooth muscle cell tumors, paragangliomas, fibromatoses, nerve sheath tumors and carcinomas. ${ }^{1}$ This is due to the relatively broad histomorphologic spectrum which GIST represents.

Surgical removal is the mainstay of treatment for nonmetastatic GIST. ${ }^{17}$ Lymph node metastases are rare hence routine removal of lymph nodes is typically not necessary. Prognosis correlates with tumor size, mitotic index, and location. ' Gastric GIST are less aggressive than those arising from the small intestine. Recurrence is rare for gastric GIST under $5 \mathrm{~cm}$ but common for mitotically active tumors larger than $10 \mathrm{~cm} .^{8}$

Imatinib, a c-kit tyrosine kinase inhibitor originally used to treat chronic myelogenous leukemia, has been found to be valuable in treating GIST. ${ }^{18}$ Imatinib is used for inoperable or metastatic cases with a $40-70 \%$ response rate. The two-year survival of patients with advanced disease has risen to $75-80 \%$ following Imatinib treatment. ${ }^{19}$ Patients who developed resistance to Imatinib may respond to the multiple tyrosinase inhibitor Sunitinib. ${ }^{20}$

In summary, gastrointestinal stromal tumors of the tongue should be considered in the differential diagnosis of a recurrent tongue mass which has been previously resected. Although GIST of the tongue is rare with only one case from Kuwait previously published, this entity should still be considered especially because GIST have previously been misdiagnosed as fibromatoses, nerve sheath tumors or carcinomas. Histopathologic and immunohistochemical studies, wherein CD117 is generally positive, aid diagnosis. Complete surgical excision is curative for most lesions. The c-kit tyrosine kinase inhibitor Imatinib is used to treat inoperable or metastatic cases.

\section{REFERENCES}

1. Miettinen M, Lasota J. Gastrointestinal stromal tumors: review on morphology, molecular pathology, prognosis, and differential diagnosis. Arch Pathol Lab Med 2006 Oct;130(10):1466-

2. Miettinen $M$, Lasota J. Gastrointestinal stromal tumors--definition, clinical, histological, immunohistochemical, and molecular genetic features and differential diagnosis. Virchows Arch 2001 Jan; 438(1):1-12.

3. Ibrahim HH, Ahmad MS, Eskaf WA, Schuutz P. Malignant gastrointestinal stromal tumor of the tongue: case report and review of the literature. Oral Surg Oral Med Oral Pathol Oral Radiol Endod. 2011 May;111(5): e24-9.

4. Anthony A, Frosch M, Girolami U. The central nervous system. In: Kumar V, Abbas A, Fausto N, Aster J. Robbins and Cotran Pathologic basis of disease. $7^{\text {th }}$ Edition, 2005. Philadelphia: Saunders Elsevier. Page 1411

5. Becker M. Oral cavity and oropharynx. In: Mafee M, Valbasson G, Becker M, Lewin JS, Nour SG, Weber AL. Imaging of the head and neck." $2^{\text {nd }}$ Edition, 2005. Stuttgart: Thieme Medical Publishers. Page 689.

6. Guo A, Liu A, Wei L, Song X. Malignant peripheral nerve sheath tumors: differentiation pattern and immunohistochemical features - a mini-review and our new findings. J Cancer 2012;3:303 309.

7. Sakurai S, Hishima T, Takazawa Y, Sano T, Nakajima T, Saito K, et al. Gastrointestinal stromal tumors and KIT-positive mesenchymal cells in the omentum. Pathol Int. 2001 Jul;51(7):524-31.

8. Tran T, Davila JA, El-Seraq HB. The epidemiology of malignant gastrointestinal stromal tumors: an analysis of 1,458 cases from 1992 to 2000. Am J Gastroentero/ 2005 Jan;100(1):162-8.

9. Rubin BP, Singer S, Tsao C, Duensing A, Lux ML, Ruiz R, et al. KIT activation is a ubiquitous feature of gastrointestinal stromal tumors. Cancer Res. 2001 Nov;61(22):8118-8121.

10. Nowain A, Bhakta H, Pais S, Kanel G, Verma S. Gastrointestinal stromal tumors: clinical profile, pathogenesis, treatment strategies and prognosis. J Gastroenterol Hepatol 2005 Jun;20(6):81824.

11. Nishida T, Hirota S. Biological and clinical review of stromal tumors in the gastrointestinal tract. Histol Histopathol 2000 Oct:15(4):1293-301.

12. Pidhorecky I, Cheney RT, Kraybill WG, Gibbs JF. Gastrointestinal stromal tumors: current diagnosis, biologic behavior, and management. Ann Surg Oncol 2000 Oct;7(9):705-12.

13. Hersh MR, Choi J, Garrett C, Clark R. Imaging gastrointestinal stromal tumors. Cancer Control 2005 Apr;12(2):111-115.

14. Ulusan S, Koc Z, Kayaselcuk F. Gastrointestinal stromal tumours: CT findings. Br J Radiol 2008 Aug;81(968):618-623.

15. Graadt van Roggen JF, van Velthuysen ML, Hogendoorn PC. The histopathological differential diagnosis of gastrointestinal stromal tumours. J Clin Pathol 2001 Feb;54(2):96-102.

16. Mazur MT, Clark HB. Gastric stromal tumors. Reappraisal of histogenesis. Am J Surg Pathol 1983 Sep;7(6):507-519.

17. Lehnert T. Gastrointestinal sarcoma (GIST)--a review of surgical management. Ann Chir Gynaecol 1988;87(4):297-305.

18. Patel SR, Wong P. The efficacy of Imatinib in unresectable/metastatic gastrointestinal tumors. US Oncological Review 2009;5(1):61-4. [Serial on the internet] Cited 2013 February 17.Available from: http://www.touchoncology.com/articles/efficacy-imatinib-unresectablemetastatic gastrointestinal-stromal-tumors.

19. Din OS, Woll PJ. Treatment of gastrointestinal stromal tumor: focus on imatinib mesylate. Ther Clin Risk Manag 2008 Feb;4(1):149 - 162.

20. Okuno SH. The use of Tyrosine kinase inhibtors for gastrointestinal stromal tumors (GIST) Contemporary Oncology.2011 Mar. [Serial on the Internet] Cited 2013 February 17. Available from: http://www.onclive.com/publications/contemporary-oncology/2011/spring-2011/theuse-of-tyrosine-kinase-inhibitors-for-gastrointestinal-stomal-tumors-gist/1. 